\title{
The Influence of Job Motivation, Perceived Organizational Support Indicators, and Demographic Characteristics on Job Satisfaction of Pharmaceutical Sales Executives in Nigeria
}

\section{Theophilus Ehidiamen Oamen}

Department of Clinical Pharmacy and Pharmacy Administration, Faculty of Pharmacy, Obafemi Awolowo University, Ife, Osun State, NIGERIA.

\begin{abstract}
Objectives: More pharmacy practice research has to be done to investigate the impact of Perceived organizational support (POS), demographics, and Job motivation (JM) on Job satisfaction (JS) of pharmaceutical sales executives (PSE) in the pharmaceutical marketing industry. The objectives of the study were to evaluate the predictive effects of POS, JM, and demographic attributes of PSE on JS. Secondly, explore the relationship between POS indicators and demographic variables of respondents. Methods: A crosssectional online survey of 406 pharmaceutical sales executives, conducted between April to May 2021 in Nigeria using a random sampling method. Results: Correlations existed between Age vs. Training and Career prospects: Marital status vs. Incentive-scheme and Career prospects: Type of pharmaceutical company vs. Work-tools availability, Training, Incentive-scheme, marketing support, and career prospects: Years of experience vs. Training, Incentive, reward system, and career prospects: Annual salary vs. worktools, Incentives, and marketing support. The study model met acceptable fit criteria. Overall satisfaction score was $1.54 \pm 0.499$, and motivation score was $1.37 \pm 0.484$ respectively. The mean satisfaction rating score was ambivalent on the 5-point scale with $2.73(\mathrm{SD}=0.90)$, and the Motivation score was $2.49(\mathrm{SD}=0.95)$ indicative of low JM. Aggregate POS $(1.88 \pm 0.734)$ and respondents' perception of the pharmaceutical marketing industry was poor $(2.10 \pm 0.83)$. The regression model showed that Marital status had a positive predictive relationship $(\beta=0.606)$ compared to Motivation ( $\beta=-$ 2.614), Reward system ( $\beta=-0.866)$, and Work tools availability $(\beta=-0.365)$, were predictors of JS at $p<0.05$. Conclusion: Study outcomes provided valuable human resource information to support policy reforms in the pharmaceutical marketing industry.
\end{abstract}

Key words: Demographics, Job satisfaction, Job motivation, Perceived organizational support, Pharmaceutical sales executives, Pharmaceutical Marketing, Nigeria, Management.

\section{INTRODUCTION}

In pharmaceutical marketing, pharmaceutical sales executives (PSE) are a critical human resource, who constantly interfaces with clients (healthcare providers, in general). They are an important factor for sustained performance and organizational success. Therefore, there is the need to examine the relationship between Job motivation (JM), perceived organizational support (POS), job satisfaction (JS), and demographic characteristics of PSE. JM reflects the state of positivity or positive energy by the employee that drives their sense of association or belonging to the purposes of the organization. Some studies have shown that decreased output and productivity were linked to a lack of
DOI: 10.5530/ijopp.15.1.3

Address for correspondence: Mr. Theophilus Ehidiamen Oamen, BPharm., MPharm; MBA; MPhil; FPCPharm,

Department of Clinical Pharmacy and Pharmacy Administration, Faculty of Pharmacy, Obafemi Awolowo University, Ife, Osun State, NIGERIA.

Email id: oamentheo@yahoo. com

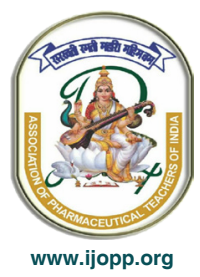


motivation. ${ }^{1-4} \mathrm{JS}$ refers to a psychological state of mind expressed as feelings of positivity and pleasure with their assessment of their jobs., ${ }^{5,6} \mathrm{JS}$ and JM have been used interchangeably in the literature, whereas JM is a driving force that drives the performance and execution of roles. ${ }^{7}$ JS, on the other hand, is a state of mind that elicits the attitudes and behaviors that support organizational goals. ${ }^{8,9}$ Furthermore, evidence from contemporary research has proven that strong relationships exist between JM and JS as higher levels of JM predict JS and vice-versa. ${ }^{4}$ Several works of literature have examined the operational components of perceived organizational support (POS) within organizations, as a critical aspect of employee perception of managements' support for their individual and overall welfare. ${ }^{10,11}$ POS is nested in organizational support theory with core components or indicators such as; adequate remuneration, fair reward system, career advancement opportunities, commendation, and promotion. ${ }^{10,12}$ Other key variables examined in this study included; Training, the prospect of promotion, and Incentives. Impact on employee performance and job satisfaction are significant as it goes a long way to affect the achievement of corporate goals and objectives. ${ }^{13-15}$ The demographic attributes of employees are considered to be one of the predisposing factors that may impact job satisfaction and invariably the desire to leave the organization. ${ }^{16}$ The role of demographic variables was explored by Amarasena et al., (2015) and Choong et al., (2013). Whereas the former study argued that age, gender, years of experience, and job status had no impact on job satisfaction, the latter study showed significant impact on job satisfaction. ${ }^{17,18}$ It is common knowledge to human resource managers that the employee is the key focal resource of an organization in the pursuit of corporate objectives. ${ }^{19-21}$ In this study, demographic variables were decomposed into individualbased attributes and occupational/organizationalbased attributes. The Individual-based attributes were; marital status, Gender, Age, educational qualification, years of experience in the present company, the total number of years in the industry. The occupational or organizational attributes considered in the study were; type of company, annual salary, and territory of coverage. The main objective of the study was to investigate the predictive effects of POS indicators, JM, and demographic attributes of PSE on JS. Secondly, to explore the relationship between POS constructs and demographic variables of respondents (PSE) in the pharmaceutical marketing industry.

\section{Study Hypothesis}

The hypotheses of the study as stated in the null were as follows;

Indian Journal of Pharmacy Practice, Vol 15, Issue 1, Jan-Mar, 2022 a) There is no relationship between demographic variables of pharmaceutical sales executives and perceived organizational support indicators of the study population $\mathrm{H} 1$.

b) There is no statistically dominant predictor of Job satisfaction among pharmaceutical sales executives in Nigeria H2.

\section{MATERIALS AND METHODS}

\section{Study population and study design}

A cross-sectional empirical online survey of pharmaceutical sales executives was conducted for 2 months (April to May 2021) across the six geopolitical zones in Nigeria using a random sampling method.

\section{Sample size determination}

Raosoft size calculator was used to determining the target sample size of respondents required for the study. ${ }^{22}$ A 5\% margin of error and 95\% confidence level was applied to a theoretical population of 25,000 pharmaceutical sales executives to give 379 .

\section{Inclusion and Exclusion Criteria}

Full-time staff with pharmaceutical companies with at least 6 months' stay. Respondents should be in companies with functional human resources departments.

\section{Ethical Approval}

Study approval was obtained from the Department of Health Planning, Research, and statistics, the Ministry of Health with reference number HPRS/381/37105/05/2021.

\section{Questionnaire design}

A questionnaire-based design was developed based on an extensive search of empirical studies associated with pharmaceutical marketing. The questionnaire was composed of two parts; Part 1 consists of the demographic characteristics of respondents. Part 2 consisted of study questions.

\section{Measures}

JM and JS were measured or evaluated on a binary scale with responses- yes or no to the questions. JS question was- 'Are you satisfied with your Job?' While the JM question was- 'Are you motivated with your Job?' The mean rating response scores were also computed. POS Indicators were measured on a 3-point Likert scale 
of 1(poor), 2(fair), and (3) good. POS was computed as an aggregate response to 5 questions on perceived organizational support received by respondents from their companies. In addition, respondents' ratings of JM, JS, and an overall view of the pharmaceutical marketing industry were rated based on a 5-point Likert scale from strongly disagree (1) to strongly agree (5), and very negative (1) to very positive (5) respectively. Mean responses were evaluated based on the Likert range; strongly disagree/very negative (1.00-1.80), disagree/negative (1.90-2.60), neither agree nor disagree/ neither negative nor positive (2.70-3.40), agree/positive (3.50-4.20), and strongly agree/very positive (4.30-5.00) respectively.

\section{Research Instrument Reliability}

The internal validity of the 5 -item variables (questions) on the respondents' perception of JS, JM, and an overall view of the industry was 0.80 . The 6-item POS indicator variables had a Cronbach alpha coefficient of 0.85 . This meets the minimum criteria for validity which was set at 0.7 .

\section{Data Analysis}

Data were analyzed using IBM SPSS version 25. Descriptive statistics such as mean and median were used to describe demographic characteristics. Binary regression modeling was used to identify the significant predictors of JS among respondents. Pearson's correlation was used to explore the relationship between POS constructs and demographic variables (Age, Gender, type of company, years of experience, territory, salary scale).

\section{RESULTS}

\section{Descriptive statistics of study variables Demographic variables}

A total of 406 responses were obtained out of 500 questionnaires administered with a response rate of $81.2 \%$ as shown in the CONSORT flowchart in Figure 1. This was about $7 \%$ higher than the projected sample size of 379; this was to cover for possible dropout in the study. The mean age of PSEs was $25.67(\mathrm{SD}=2.45)$ within a range of 20 to 50 years. Majority of respondents are married $(57 \%, n=230)$, unmarried $(43 \%, n=173)$ and the lowest, was divorced $(7 \%, n=3)$. Two hundred and ninetythree representing approximately $72 \%$ of respondents were males compared to one hundred and thirteen (28\%) females. Approximately $61 \%$ work in multinational pharmaceutical companies while 39\% work with Nigerian-owned companies. Furthermore, years of

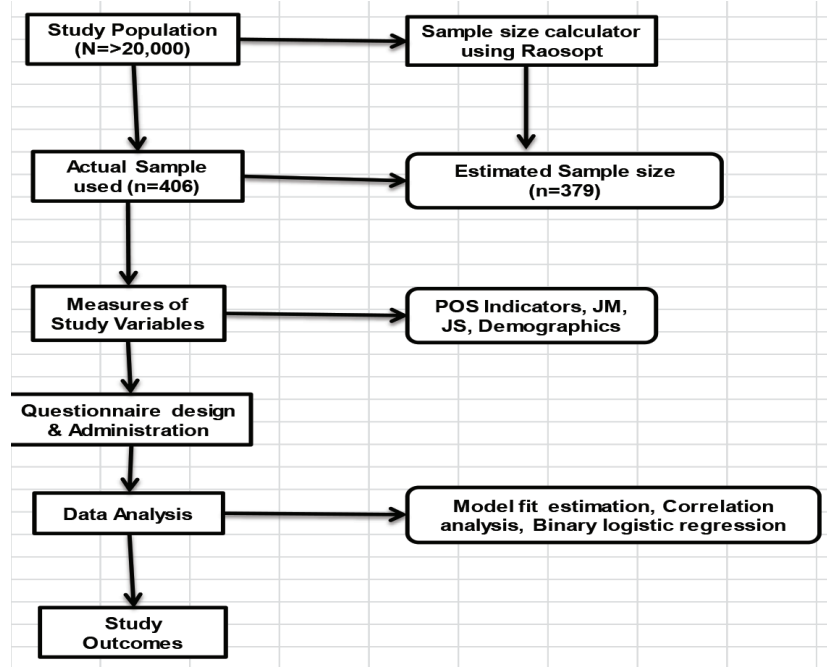

Figure 1: CONSORT Flow Chart of Study.

experience in the present company was $2.19 \pm 0.82$, total years of industry experience was $2.53 \pm 0.86$, Territory of coverage was $2.21 \pm 1.70$. Comparison between mean years of experience in the present company and years of experience in pharmaceutical marketing showed a significant difference in favor of total years of experience in the study population (mean $=0.345, \mathrm{SD}=0.72,95 \%$ confidence interval- 0.274 to 0.415$), p<0.001$ ).

\section{Perceived Organizational Support (POS) Indicators}

Mean scores of Indicators measured on an ordinal scale of $1=$ poor, $3=$ fair, and $5=$ good were computed. Work tools availability was $2.08(\mathrm{SD}=0.778)$, Training opportunities was $1.97(\mathrm{SD}=0.723)$, Incentive schemes was 1.72 ( $\mathrm{SD}=0.755)$, Marketing support was $1.90(\mathrm{SD}=0.726$, the Reward system was $1.76(\mathrm{SD}=0.689)$, and Career advancement prospects were $1.85(\mathrm{SD}=0.719)$. The aggregate mean score of POS Indicators was 1.88 $(\mathrm{SD}=0.734)$.

\section{JS, JM, and Overall Industry Perception by Respondents}

The overall satisfaction score was $1.54 \pm 0.499$, and the overall motivation score was $1.37 \pm 0.484$. The mean satisfaction score on the 5-point scale was 2.73 $(\mathrm{SD}=0.90)$, the Motivation score was $2.49(\mathrm{SD}=0.95)$, and the overall perception of the pharmaceutical marketing industry was 2.10 ( $\mathrm{SD}=0.83)$. Comparison between mean satisfaction and motivation scores showed significant difference in favor of satisfaction in the study population (mean $=0.255, \mathrm{SD}=0.755,95 \%$ confidence interval-0.180 to 0.33$), p<0.001)$.

Indian Journal of Pharmacy Practice, Vol 15, Issue 1, Jan-Mar, 2022 


\section{Model fit Evaluation}

The fit of the stepwise regression model for models 1,2 , 3 , and 4 was confirmed by the following parameters as shown in Table 1. Model fit characteristics $(\chi 2(\mathrm{~d} f=1,2,3$, and $4, \mathrm{~N}=406)=120.356,142,768,149,202$, and 153,262 respectively) were significant predictors at $p<0.05$; Goodness of fit expressed by Pearson $\chi 2(\mathrm{~d} f)$, and $p$-value greater than 0.05 proved that model is fit since the $p$-value is not significant from model 1 to 4; prediction accuracy for all models were above the threshold of 50\%; and Nagelkerke $\mathrm{R}^{2}$ (ranged from $34.3 \%$ to $42.0 \%$ ) and Cox and Snell R ${ }^{2}$ (ranged from 0.257 to 0.314 ) for model 1 to 4. The change in Snell and Cox Indicator $\mathrm{R}^{2}$ in each model 1,2,3, and 4 measured the possible increase in the predictive capacity of the independent variables given the dependent variable. Results in Table 1 showed that model 4 had the highest $\mathrm{R}^{2}$ compared to the others.
The correlation analysis output in Table 2 showed that Gender and Territory of coverage did not show any relationship with perceived organization support indicators $(p>0.05)$. Age showed a significant negative relationship with Training and Career prospects. Marital status has a significant positive relationship with the Incentive scheme and Career prospects. Type of pharmaceutical company had a highly significant relationship with work tools availability, Training, Incentive scheme, marketing support, and career prospects. However, Years of experience in the present firm showed a negative correlation with Training, Incentive, reward system, and career prospects. Finally, the Annual salary showed a significant positive relationship with work tools, Incentives, and marketing support only.

In Table 3, the output of the stepwise binary regression model showed that independent (Predictor) variables;

Table 1: Model fit characteristics of Stepwise Regression Model.

\begin{tabular}{cccccccccc} 
Models & $\mathbf{X}^{2}$ & $\mathbf{d}_{\mathbf{f}}$ & $\boldsymbol{P}$-value & $\begin{array}{c}\text { \% Prediction } \\
\text { accuracy }\end{array}$ & $\begin{array}{c}\text { Cox and Snell } \\
\boldsymbol{R} \text { square }\end{array}$ & $\begin{array}{c}\text { Nagelkerke } \boldsymbol{R} \\
\text { square }\end{array}$ & $\begin{array}{c}\text { The goodness } \\
\text { of fit }\left(\mathbf{X}^{2}\right)\end{array}$ & $\mathbf{d}_{\mathbf{f}}$ & $\boldsymbol{P}_{\text {-value }}$ \\
\hline 1 & 120.356 & 1 & 0.001 & 74.1 & 0.257 & 0.343 & 0.000 & 0 & \\
2 & 142.768 & 2 & 0.001 & 74.9 & 0.296 & 0.396 & 1.478 & 3 & 0.687 \\
3 & 149.202 & 3 & 0.001 & 76.1 & 0.308 & 0.411 & 2.646 & 6 & 0.852 \\
4 & 153.262 & 4 & 0.001 & 74.3 & 0.314 & 0.420 & 6.582 & 8 & 0.582 \\
\hline
\end{tabular}

Note: $p<0.05$ is significant, chi-square $=\mathrm{X}^{2}$, Hosmer-Lemeshow test=goodness of fit, $\mathrm{d} f=$ degree of freedom

Table 2: Correlation Analysis of Perceived Organizational Support Indicators and Demographic Characteristics of Study Population ( $N=406$ ).

\begin{tabular}{|c|c|c|c|c|c|c|c|}
\hline Study Variable & $\begin{array}{c}\text { Pearson/ } \\
p \text {-value }\end{array}$ & $\begin{array}{l}\text { Work } \\
\text { Tools }\end{array}$ & Training & Incentive & $\begin{array}{c}\text { Marketing } \\
\text { Support }\end{array}$ & $\begin{array}{l}\text { Reward } \\
\text { System }\end{array}$ & $\begin{array}{c}\text { Career } \\
\text { Prospects }\end{array}$ \\
\hline \multirow[t]{2}{*}{ Gender } & $r$ & 0.053 & 0.074 & -0.016 & 0.048 & 0.006 & 0.018 \\
\hline & $p$-value & 0.289 & 0.139 & 0.751 & 0.337 & 0.908 & 0.723 \\
\hline \multirow[t]{2}{*}{ Age } & $r$ & -0.043 & $-.124^{*}$ & -0.051 & -0.073 & -0.054 & $-.125^{*}$ \\
\hline & $p$-value & 0.389 & 0.013 & 0.303 & 0.143 & 0.279 & 0.012 \\
\hline \multirow[t]{2}{*}{ Marital Status } & $r$ & -0.012 & 0.075 & $.111^{*}$ & 0.070 & 0.071 & $.131^{* *}$ \\
\hline & $p$-value & 0.804 & 0.130 & 0.025 & 0.160 & 0.151 & 0.008 \\
\hline \multirow[t]{2}{*}{ Type of Company } & $r$ & $.240^{* *}$ & $.243^{* *}$ & $.243^{* *}$ & $.204^{* *}$ & 0.095 & $.114^{*}$ \\
\hline & $p$-value & 0.000 & 0.000 & 0.000 & 0.000 & 0.056 & 0.021 \\
\hline \multirow{2}{*}{$\begin{array}{c}\text { Years of experience in } \\
\text { present company }\end{array}$} & $r$ & -0.052 & $-.169^{* *}$ & $-.100^{*}$ & -0.087 & $-.121^{*}$ & $-.124^{*}$ \\
\hline & $p$-value & 0.300 & 0.001 & 0.045 & 0.079 & 0.015 & 0.012 \\
\hline \multirow{2}{*}{$\begin{array}{l}\text { Years of Industry } \\
\text { Experience }\end{array}$} & $r$ & -0.037 & $-.186^{* *}$ & $-.112^{*}$ & $-.102^{*}$ & $-.154^{* *}$ & $-.133^{* *}$ \\
\hline & $p$-value & 0.453 & 0.000 & 0.024 & 0.040 & 0.002 & 0.007 \\
\hline \multirow[t]{2}{*}{ Territory } & $r$ & -0.038 & 0.013 & -0.004 & -0.020 & -0.032 & 0.086 \\
\hline & $p$-value & 0.450 & 0.792 & 0.930 & 0.686 & 0.520 & 0.083 \\
\hline \multirow[t]{2}{*}{ Annual Salary } & $r$ & $.194^{* *}$ & 0.064 & $.118^{*}$ & $.119^{*}$ & 0.068 & 0.047 \\
\hline & $p$-value & 0.000 & 0.200 & 0.017 & 0.016 & 0.170 & 0.341 \\
\hline
\end{tabular}

Note; ${ }^{*} \mathrm{p}<0.05: * * p<0.01$ (2-tailed test), $r=$ Pearson's correlation coefficient, 


\begin{tabular}{ccccccccccc}
\multicolumn{2}{c}{ Table 3: Logistic Regression Analysis Output of Significant Predictor Variables of Job satisfaction. } \\
Models & $\begin{array}{l}\text { Predictor } \\
\text { Variables }\end{array}$ & $\begin{array}{c}\boldsymbol{\beta} \\
\text { estimate }\end{array}$ & SE & Wald & $\mathbf{d}_{\mathbf{f}}$ & $\boldsymbol{P}$-value & $\begin{array}{c}\operatorname{Exp}(\boldsymbol{\beta}) \\
\text { OR }\end{array}$ & LCI & UCI \\
\hline 1 & Motivation & -2.614 & 0.279 & 87.876 & 1 & 0.000 & 0.073 & 0.042 & 0.127 \\
2 & Reward System & -0.866 & 0.188 & 21.219 & 1 & 0.000 & 0.421 & 0.291 & 0.608 \\
3 & Marital Status & 0.606 & 0.241 & 6.312 & 1 & 0.012 & 1.833 & 1.143 & 2.942 \\
4 & Work Tools & -0.365 & 0.182 & 4.052 & 1 & 0.044 & 0.694 & 0.486 & 0.990 \\
& availability & & & & & & & &
\end{tabular}

$p<0.05, \mathrm{SE}=$ standard error: $\mathrm{OR}=$ odd ratio: $\mathrm{LCl}=$ lower confidence interval: $\mathrm{UCl}=$ upper confidence interval

Motivation, Reward system, Marital status, and Work tools availability were all statistically significant predictors of the dependent (outcome) variable Job satisfaction (JS). The $\operatorname{Exp}(\beta)$ or Odds ratio (OR) represents the odds that a particular explanatory or independent variable will predict JS (satisfaction or not) in the study population. However, only Marital status had a positive predictive relationship $(\beta=0.606)$ compared to Motivation ( $\beta=-2.614)$, Reward system $(\beta=-0.866)$, and Work tools availability $(\beta=-0.365)$ with negative regression coefficients. In the stepwise model, age, gender, type of company, years of experience in the present company, total years of experience in the industry, Territory of coverage, and Annual Salary did not show any statistical influence on JS in the model, hence their exclusion from the regression output.

\section{DISCUSSION}

The study examined the influence of demographic attributes of PSEs, POS Indicators, and Job motivation on JS of PSEs in the pharmaceutical industry in Nigeria. The study also examined the relationship between POS indicators of the study population and demographic characteristics. Several hypotheses were tested in the study based on study outcomes. In Table 1, the correlation matrix revealed significant relationships existed between demographic variables and POS indicators; hence the null hypothesis (H1) was rejected. Mean satisfaction and motivation scores as rated by respondents revealed low levels in the workforce: satisfaction score $(\mathrm{m}=2.73$, $\mathrm{SD}=0.90$ ) on a 5 -point Likert scale revealed ambivalence as to whether or not they are satisfied with their jobs. This ambivalence or uncertainty expressed in this study is corroborated by a study that assessed job satisfaction among teachers. ${ }^{23}$ However, the mean score for motivation was low $(\mathrm{m}=2.49, \mathrm{SD}=0.95)$ as it depicted overall low motivation rates among sales executives $(p<0.01)$. This finding invariably suggests a negative impact on JS in the long run. This is at variance with the expectation that suggests a positive JS level implies an improvement in JM among employees. ${ }^{2,3}$ This is because causal relationships have been shown to exist between JS and JM in the literature. ${ }^{4}$ The low means scores of JS and $\mathrm{JM}$ among respondents are linked to low aggregate levels of POS $(\mathrm{m}=1.88, \mathrm{SD}=0.734)$ as reflected by the relatively low mean scores of POS Indicators which summarizes overall poor working conditions. The indicators such as: low work tools availability $(\mathrm{m}=2.08, \mathrm{SD}=0.778)$, unattractive remuneration $(\mathrm{m}=1.76, \mathrm{SD}=0.689)$, slow career paths $(\mathrm{m}=1.85, \mathrm{SD}=0.719)$, and poor incentive schemes $(m=1.72, S D=0.755)$ attests to this reality in the sector. ${ }^{23}$

The regression model as shown in Table 3 was interpreted thus; in model 1, pharmaceutical sales representatives in the motivated category, are $83 \%(\mathrm{OR}=1.00-0.073)$ less likely to be dissatisfied with their jobs compared to those who are satisfied with their jobs. This confirms a higher level of satisfaction. In model 2, in the study population, for every unit increase in the reward system, PSEs are about 58\% (1.000-0.421) less likely to experience or have job dissatisfaction compared to the reference group (those with job satisfaction). This supports the theory that higher and/or improved reward systems would elicit higher JS from employees and invariably positively impact overall job performance compared to companies with poor reward systems. ${ }^{24,25}$ In model 3 , for every unit change in marital status, there is an 83.3\% increase in (1.833-1.000) likelihood for PSEs to be dissatisfied with their jobs compared to the satisfied group. This holds true in particular for those married who represented the largest proportion of respondents $(n=230,56.7 \%)$ compared divorced $(n=3,7 \%)$ and unmarried $(n=173,42.6 \%)$ PSEs. This finding aligns with a study that compared JS among married and unmarried persons. ${ }^{26}$ In model 4, based on the predictor- work tools availability, the $\log$ odds of dissatisfaction with their jobs decreases by 0.693 . In other words, for every unit increase in the work tools availability, PSEs have a 30.4\% decreased likelihood to be dissatisfied with their jobs. This implies that the availability of work tools such as functional vehicles, fueling allowance, timely provision of required resources, and promotional materials, invariably enhances JS. This finding is supported 
by studies that focused on the impact of adequate resources to support employee's job performance and job roles. ${ }^{12,27-29}$ The significant predictors in the regression model confirmed the rejection of the null hypothesis (H2).

There are salient implications of the study outcomes on pharmaceutical marketing management applicable to developing countries like Nigeria. Ensuring acceptable levels of overall JS and JM among pharmaceutical sales executives is imperative for management. This is essential to facilitate dedication and growth for the industry. Hence, it is recommended that management strive to harmonize or improve human resource policies and frameworks to enhance adequate remuneration, welfare-conducive working environments for staff. Secondly, employee capacity to adapt to changing work situations and dynamics can be enhanced by regular and impactful training in addition to staff engagements feedback mechanisms. These measures will improve perceived support from the perspective of PSEs and invariably engender more productivity. This study provides preliminary information for policy reforms in the pharmaceutical marketing industry.

\section{CONCLUSION}

The study findings showed that PSE's overall rating of satisfaction and motivation was generally low (compared to the median values on the 5-point Likert scale). This reflects the need for improvement on the part of management teams in pharmaceutical firms. Study outcomes revealed that the overall JS and JM were low. Several relationships existed between demographic attributes and some POS indicators. The apparent ambivalence of mean rating response to JS and JM was indicative of the uncertainty of PSE's as to whether they are satisfied with their jobs or not. There is a need for the management of pharmaceutical companies to adopt policies that consider the demographic attributes of their employees in designing their welfare packages.

\section{ACKNOWLEDGEMENT}

I hereby appreciate the pharmaceutical sales executives who filled the questionnaires. And my gratitude goes to the management staff of pharmaceutical companies pan Nigeria who helped to facilitate the process.

\section{CONFLICT OF INTEREST}

The authors declare that there is no conflict of interest.

\section{ABBREVIATIONS}

JS: Job satisfaction; JM: Job motivation; POS: Perceived organizational support; PSE: pharmaceutical sales executives; LCI: lower confidence interval; UCI: upper confidence interval.

\section{Limitations of the study}

The sample size was small: hence extrapolation to the larger population should be done with caution. The target population in the study was the on-the-field sales executives. Therefore, there is a need for further studies on JS of office-based staff should also be explored.

\section{Consent to Participate}

Before questionnaire administration, participants were briefed on the purpose of the research and assured of absolute anonymity. Participants gave their informed consent before answering the questionnaire.

\section{REFERENCES}

1. Parvin MM, Kabir MMN. Factors affecting employee job satisfaction of pharmaceutical sector. Aust J Bus Manag Res. 2011;1(9):111-23.

2. Irakoze E, David KG. Linking Motivation to Employees' Performance: the Mediation of Commitment and Moderation of Delegation Authority. Int Bus Res. 2019;12(9):13-28, doi: 10.5539/ibr.v12n9p13.

3. Maduka CE, Okafor O. Effect of Motivation on Employee Productivity; A study of Manufacturing Companies in Nnewi. Int J Manag Stud Res. 2014;2(7):137-47.

4. Lee MT, Raschke RL, Louis RS. Exploiting organizational culture: configurations for value through knowledge worker's motivation. J Bus Res. 2016;69(11):5442-7. doi: 10.1016/j.jbusres.2016.04.152.

5. Alam S, Shahi M. Factors affecting job satisfaction, motivation, and turnover rate of medication officer (MPO) in the pharmaceutical industry: a study based in Khulna city. Asian Bus [review]. 2015;1(2):126-31.

6. Haroon M, Zaman HMF, Rehman W. The relationship between Islamic work ethics and job satisfaction in the healthcare sector in Pakistan. Int $\mathrm{J}$ Contemp Bus Stud. 2012;3(5):6-12.

7. Chaudhary N, Sharma B. Impact of employee motivation on Performance (Productivity) in private organizations. Int J Bus Trends Technol. 2012;2(4):19-35.

8. Shah N, Irani Z, Sharif AM. Big data in an HR context: exploring organizational change readiness, employee attitudes and behaviors. J Bus Res. 2017;70:366-78. doi: 10.1016/j.jbusres.2016.08.010.

9. Alegre I, Mas-Machuca M, Berbegal-Mirabent J. Antecedents of employee Job satisfaction: do they matter? J Bus Res. 2016;69(4):1390-5. doi: 10.1016/j. jbusres.2015.10.113.

10. Eisenberger R, Armeli S, Rexwinkel B, Lynch PD, Rhoades L. Reciprocation of perceived organizational support. J Appl Psychol. 2001;86(1):42-51. doi: 10.1037/0021-9010.86.1.42, PMID 11302232.

11. Rhoades L, Eisenberger R. Perceived Organizational support; A review of the Literature. J Appl Psychol. 2002;87(4):698-714. doi: 10.1037/00219010.87.4.698, PMID 12184574.

12. Monica Hu M, Anne Chang H. The Effect of Perceived Organization Support on the Motivation for a Licence Examination. Asia Pac J Tourism Res. 2008;13(1):19-32. doi: 10.1080/10941660701883342.

13. Mohamed SA, Maimunah A. The influence of perceived organizational support on employee job performance. Int J Sci Res Publ. 2015;5(4):1-6.

14. Salton E, Nsiah S. The mediating and moderating effects of motivation in the relationship between perceived organizational support and employee job performance. Int J Econ Manag. 2015;3(7):654-67. 
15. Maan AT, Abid G, Butt TH, Ashfaq F, Ahmed S. Perceived organizational support and job satisfaction: a moderated mediation model of proactive personality and psychological empowerment. Futur Bus J. 2020;6(1):21. doi: 10.1186/s43093020-00027-8.

16. Belete AK. Turnover intention influencing factors of employees; an empirical work review. J Entrep Organ Manag. 2018;7:3. doi, doi: 10.4172/2169026X.1000253.

17. Amarasena TSM, Ajward AR, Haque AKM. The effects of demographic factors on Job satisfaction of University Faculty members in Sri Lanka. Int J Acad Res Refl. 2015;3(4):89-106.

18. Choong YO, Keh CG, Tan YT, Tan CE. Impacts of Demographic Antecedents towards Turnover Intention amongst Academic staff in Malaysia Private Universities. Aust J Basic Appl Sci. 2013;7:46-54.

19. Allen DG, Shore LM, Griffeth RW. The role of perceived organizational support and supportive human resource practices in the turnover process. J Manag. 2003;29(1):99-118, doi: 10.1177/014920630302900107.

20. Ageeva E, Melewar TC, Foroudi P, Dennis C, Jin Z. Examining the influence of corporate website favorability on corporate image and corporate reputation: findings from fsQCA. J Bus Res. 2018;89:287-304. doi: 10.1016/j. jbusres.2018.01.036.

21. Del-Castillo-Festo C, Blanco-Gonzalez A, Gonzalez-Vasquez E. The relationship between image and reputation in the Spanish public university. Eur J Manag Bus Econ. 2018;25(2):87-92. doi: 10.1007/s1065.
22. Raosoft. Sample size calculator [online]. HTML> 2016. Available from: http:// www.raosft.com/samplesize. [accessed December 2020].

23. Chirchir R. Demographic Factors and Job Satisfaction: A case of Teachers in Public primary schools in Bomet, Kenya. J Educ Pract. 2016;7(13):152-8.

24. Opkara JO. The impact of salary differential on managerial job satisfaction: A study of the gender gap and its implications for management education and practice in a developing economy. J Bus Dev Natl. 2002;2002(8):65-92.

25. Nurcahyono HB, Mardian E. The effect of demographic characteristics, remuneration, job redesign on employee performance with job satisfaction as mediation. Int J Bus. 2019;18(1):265-72.

26. Tabatabaei S, Ghaneh S, Mohadder H, Khansari MM. Relationship of job satisfaction and demographic variables in pars cream factory employees in Iran. Counseling and guidance. Procedia Soc Behav Sci. 2013;2013(84):1795-800.

27. Mostafijor R, RazwanHasan KC, Abdul K, Amirul I, Ummay T. Exploring the relationship between demographic characteristics and job satisfaction Indicators: A study on Private bank employees in Bangladesh. J Entrep Organ Manag. 2021;10(4).

28. Oamen TE. An exploratory factor analysis of work attributes of pharmaceutical sales workforce during COVID-19 lockdown. J Contemp Res Soc Sci. 2021;3(1):11-27. doi, doi: 10.33094/26410249.2021.31.11.27.

29. Oamen TE, Omorenuwa OS. The nexus of perceived organizational support, job satisfaction, job motivation on the turnover intentions of pharmaceutical sales executives using structural equation modeling. Glob J Manag Bus Res. 2021:21(9):45-53. doi. 10.34257/GJMBRAVOL21IS9PG45. 